\title{
Sweat rate and environmental factors in junior Laser class sailors
}

\author{
Guillermo J. Lorenzo González', Jano Toro Prieto-Puga², Teresa Seoane Pillado³, Emiliano Fernández Windscheid4 \\ 'Servicio de Urgencias. Sección Pediatría. Complexo Hospitalario Universitario de Ferrol. A Coruña. ${ }^{2}$ Real Federación Española de Vela. Santander. Cantabria. Instituto de Investi- \\ gación Biomédica de A Coruña (INIBIC). Departamento de Ciencias de la Salud. Universidad de A Coruña. A Coruña. ${ }^{4}$ Servicio de Cardiología. Complexo Hospitalario Universitario \\ de Ferrol. A Coruña.
}

doi: $10.18176 /$ archmeddeporte.0003

Recibido: 30/10/2019

Aceptado: $23 / 05 / 2020$

Key words: Nutrition. Youth. Exercise. Performance.

\section{Summary}

Introduction: Recent studies have reported differences in sweat rate (SR) in laser class (LC) sailors under extreme environmental conditions (EC). This study aimed to determine a'standard-like'SR in junior Laser 4.7 sailors under'not-extreme' weather conditions to achieve an adequate fluid replacement rate for training and racing sessions. Additionally, we analysed the hypothetical relationship between SR and certain environmental factors, not just considering them as independent variables, but also including them as a whole factor, usually known as 'windchill' (WCh).

Material and method: Nine male elite junior Laser 4.7 class athletes were included in this descriptive study. They were monitored during the entire year of training and racing sessions, including national and international championships. Body mass changes as well as their food and fluid intake were measured for each sailor before and after sailing to estimate SR, absolute body mass change, and percentage body mass variation for all the sessions. Athletes were asked to maintain "ab libitum" fluid and food intake during the study. Environmental temperature, wind speed, and relative humidity were measured.

Results: Significant differences $(p=0.012)$ were observed between training and racing sessions with respect to SR, 0.18 ( \pm $0.14)$ L.h ${ }^{-1}$ vs. $0.23\left( \pm 0.12{\mathrm{~L} . \mathrm{h}^{-1}}^{-1}\right.$. Environmental temperature and WCh during racing showed an inverse relationship with SR. Discussion: This result suggests that increased fluid and food intake are required under cold weather conditions to maintain the 'target' weight during the competitions and improve performance.
Palabras clave: Bicarbonato sódico. Alta intensidad. Rendimiento físico. Personal militar.

\section{Tasa de sudoración y factores ambientales en regatistas juveniles de clase Láser}

Resumen

Introducción: Recientemente, algunos estudios han reportado diferencias en la tasa de sudoración (SR) en regatistas de clase láser (LC) bajo condiciones ambientales (EC) extremas. Este estudio pretende determinar una especie de "SR standard" en regatistas juveniles de Láser 4.7 bajo condiciones "no extremas", con el objetivo de alcanzar una adecuada reposición de líquidos tanto para entrenamientos como en competición. Adicionalmente, se ha analizado una hipotética relación entre SR y los factores ambientales, considerándolos no únicamente como variables independientes, sino también como una variable compleja, conocida habitualmente como "sensación térmica" (WCh).

Material y método: Nueve regatistas juveniles de Láser 4.7 han participado en este estudio descriptivo y prospectivo. Todos ellos han sido monitorizados durante todo un año de sesiones de entrenamiento y competición, incluyendo regatas nacionales como internacionales. Los cambios en la masa corporal, así como la ingesta de líquidos y sólidos han sido registrados de forma individual para cada regatista, antes y después de cada sesión para estimar la SR, los cambios totales en la masa corporal, así como las variaciones en el porcentaje de masa corporal. Se instó a los regatistas a ingerir comida y bebida "ab libidtum"a lo largo del estudio. La temperatura ambiental, la intensidad de viento y la humedad relativa fueron registradas. Resultados: Se observaron diferencias significativas $(p=0,012)$ para la SR entre los entrenos y las competiciones $0,18( \pm 0,14)$ L.h ${ }^{-1}$ vs. 0,23 ( \pm 0,12 L.h $\left.{ }^{-1}\right)$. La temperatura ambiental y la WCh durante las competiciones mostraron además una relación inversa con la SR.

Discusión: Estos resultados sugieren que una mayor ingesta de líquidos y sólidos bajo condiciones de "frío ambiental" es necesaria para mantener el peso ideal, mejorando así el rendimiento durante la competición. 


\section{Introduction}

Dehydration is a term that usually reflects any loss of body water and is associated with poor athletic performance, heat-induced illness, skeletal muscle cramps, and acute renal failure in athletes. The American College of Sports Medicine uses non-invasive measures to define dehydration (a urine specific gravity of $\geq 1.020$ and/or urine osmolality of $\geq 700$ $\mathrm{mOsmol} / \mathrm{kgH}_{2} \mathrm{O}$ ). Additionally, in 2007, the American College of Sports Medicine proposed that 'dehydration (loss of water greater than $>2 \%$ of body weight) decreases aerobic exercise performance in temperate and warm-hot environments and that greater levels of dehydration will further decrease aerobic exercise performance ${ }^{\prime 1}$.

While adequate intake of carbohydrates, fluid, and electrolytes is an important factor for improving endurance sports performance ${ }^{2,3}$, progressive levels of exercise-induced dehydration during sport activities have shown to be associated with increased thirst and negative mood ratings; this, in turn, would limit cognitive function, reducing aerobic endurance exercise performance and resulting in increased body temperature, heart rate, and perceived exertion ${ }^{4}$.

Although a small decrement in hydration status has been shown to impair the physiologic function and performance of runners while running in the heat ${ }^{5}$, some studies suggested that athletes of endurance sports who run regularly ingest less than adequate fluid to maintain hydration, even if provided with ad libitum drinks ${ }^{6}$. Moreover, ab libitum fluid intake is not enough to prevent dehydration in suboptimally hydrated young soccer players ${ }^{7}$. Several studies using body weight and urine indices as outcome measures support the conclusion that athletes must drink beyond the physiological dictates of thirst to maintain adequate hydration levels ${ }^{1,8}$. This insufficient self-voluntary fluid intake indicated that thirst is not an adequate mechanism to appropriately maintain hydration status during prolonged endurance exercise $e^{9,10}$. However, there was disagreement between the results of previous studies on the rates of voluntary dehydration between athletes during practise?

In one of the first studies on hydration and sport performance ${ }^{11}$, explained that 'during exercise, sweat output often exceeds water intake, which results in a body water deficit or hypohydration. Aerobic exercise tasks are likely to be adversely affected by hypohydration; moreover, the warmer the environment, the greater the potential for performance decrements'.

A recent review concluded that dehydration has a negative impact on physical performance for activities lasting more than 30 seconds. Although exercise itself can help achieve a 'hypohydration state', the level of dehydration induced may depend on several, factors, including the type, intensity, and duration of the exercise and the temperature and humidity of the environment ${ }^{12}$.

In early 90s, some researchers suggested that SR and water loss seem to be affected by environmental conditions $(E C)^{13}$. Therefore, it seems logical to suspect that the variability of environmental factors and their effects on sport performance could be increased when associated with outdoor sport practice. Although several studies have examined the physiology of players participating in dinghy racing and other sports involving the use of small sail boats in the past 20 years, evidence-based knowledge on sailing and the associated physiological demands is limited compared to that on other endurance sports. However, the current interest in research by groups, such as Olympic and America's Cup teams, has led to beneficial changes ${ }^{14}$.

The Laser class (LC) is one of the most popular single- handed dinghies in the world. The Laser became a men's Olympic class boat at the 1996 Summer Olympics in Atlanta. A version with a smaller sail, the Laser Radial was first sailed as a women's Olympic class boat at the 2008 Summer Olympics. Laser 4.7 is the version with the smallest sail and is often sailed by young sailors, usually aged below 18 years, before reaching the greater versions. Fast Laser sailing requires an advanced level of fitness, especially in the quadriceps, abdominal muscles, and upper back muscles, to endure the straight legged hiking and bodytorque techniques essential in getting upwind and reaching quickly ${ }^{15,16}$. Physiological requirements in Elite dinghy sailors (including LC) seem to be similar to other endurance sports, such cycling and running ${ }^{14,17}$. Evaluation of the energy demands of $L C$ sailors revealed that there was a direct correlation between wind velocity and the energy demand during sailing ${ }^{18}$. Although some authors initially suggested that dinghy sailing performance is primarily sustained by the anaerobic metabolism, their studies did not reproduce real racing conditions, because the mean duration of exercise on water varied from 10 to 20 minutes $^{19,20}$. In fact, regattas last for 30-45 minutes; thus, most recent studies suggested that aerobic capacity could be a determinant of an elite Laser athlete's performance.

On reproducing real on-water racing conditions for 30 minutes or more, some studies reported that the physiologic response to sailing in moderate winds could be used to determine the energy requirements, which are largely met by the aerobic metabolism especially in higher skilled Laser sailors ${ }^{18}$.

Although the evidence suggest that the maintenance of hydration status is a fundamental factor to achieve the best level for athletic performance, only a limited number of studies examined the hydration requirements of Olympic class sailors compared with other endurance sports ${ }^{16}$. Studies showed that most participants experience a negative fluid balance after three consecutive races (95 minutes of racing and 5 hours on water) in a Laser and Laser radial club level regatta. The results showed that most participants presented with negative fluid balance after racing (men: mean, $-2.1 \%$ [95\% confidence limits, $-1.7 \%$ to $-2.5 \%]$; women: mean, $-0.9 \%$ [0\% to $-1.8 \%]$ ), most likely due to low voluntary fluid intake. However, the periods of'rest' between races could result in the underestimation of these results ${ }^{17}$.

Previously ${ }^{21}$, reported that the elite New Zealand Olympic class dinghy sailors also demonstrated a lack of knowledge regarding sports nutrition and guidelines for fluid consumption during exercise. Moreover, no significant differences were observed in the nutrition habits between sailors who received nutrition sport science support (SSS) and those who did not receive SSS in 1994-199522. In a recent study assessing the hydration status of elite young Laser athletes of a Greek national sailing team during a 4-day World Championship competition, results showed that pre-race body weight was significantly and progressively decreased on days 2, 3, and 4 compared with the 3-day baseline value, indicating progressive dehydration. The highest degree of dehydration was observed on the 4 th racing day (pre: $-2.9 \pm 0.1 \%$ and post: $-5.8 \pm 0.2 \%$ of body weight) ${ }^{23}$. 
In another study including 11 male Olympic sailors, a fixed volume of $11.5 \mathrm{~mL} . \mathrm{kg}^{-1} \cdot \mathrm{h}^{-1}$ was consumed during 'warm environmental condition (WEC)' training, and hydration status was maintained by preventing changes in body mass and urine specific gravity. However, in the same study, it showed that the ab libitum fluid consumption in cold environmental conditions (CEC) was insufficient in preventing a decrease in body mass and blood electrolyte concentration post-training. Additionally, notable differences between laboratory and on-water SR for warm conditions were observed ${ }^{16}$.

\section{Purpose of the study}

Therefore, it is important to note that laboratory sweat testing results did not directly correspond to the on-water SR. This finding may guide further research on the hydration requirements of sailors in different EC. The present study aimed to evaluate the on-water training and racing sweat rates (SRs) in young Laser 4.7 elite athletes. It also aimed to determine the hypothetical relationship between EC and SR.

\section{Material and method}

\section{Participants}

Nine male LC 4.7 young sailors volunteered for an investigation to assess body mass changes under diverse weather conditions during training sessions (TS) and racing sessions (RS) for a year (October 2015 to September 2016). The mean age and weight at the beginning of the study were 15,9 \pm 1.4 years and 64,1 $\pm 8.1 \mathrm{~kg}$. Body mass index (BMI) was $23 \pm 4,2$ (Table 1).

All participants and their legal guardians were informed of the objective of the study, and they provided written informed consent prior to the start of the study. The study was approved by the Research Ethics Committee of Galicia (Spain) and was carried out in accordance with the Helsinki Declaration. Support for the methodological and data analyses was obtained from the Clinical Researching Committee, Unidad de Investigación Clínica y Ensayos Clínicos (UICEC) de A Coruña (Spain). Athletes who were invited to participate in the Spanish National LC 4.7 Championship and without chronic illness were included.

Table 1. Demographic characteristics of participants.

\begin{tabular}{lcc}
\hline & M & SD \\
\hline Age (years) & 15.9 & 1.4 \\
BMI (kg/m $\mathrm{m}^{2}$ & 23 & 4.2 \\
Weight $(\mathrm{kg})$ & 64.1 & 8.1 \\
Height $(\mathrm{cm})$ & 173.9 & 6.9 \\
Sailing experience (years) & 6.8 & 1.8 \\
\hline
\end{tabular}

BMI: Body Mass Index.

Body mass index (BMI) is a value derived from the mass (weight) and height of a person (Keys et al, 1972). The BMI is defined as the body mass divided by the square of the body height, and is universally expressed in units of $\mathrm{kg} / \mathrm{m}^{2}$.

\section{Design}

Body weight after voiding was measured digitally and recorded to the nearest $100 \mathrm{~g}( \pm 0.1 \mathrm{~kg}$ ) (Model 803, Seca, Hamburg, Germany) approximately 10 minutes before departure. Athletes were weighed again 10 minutes after each session. They were towel dried and weighed while wearing minimal clothing. Data from sailors confirming bladder/ bowel evacuation between pre and post measurements were removed from the analysis.

The participants had ad libitum access to water and food intake while sailing. Data were individually collected and recorded for each session and sailor. Athletes were asked to keep all food and fluid packaging for recording.

Amount of fluid consumption were measured to the nearest $10.0 \mathrm{~mL}$ of translucent, graduated bottles before and after each session, and the difference were recorded.

Food was provided as energy bars (Powerbar ${ }^{\circ}$, Active Nutrition International $\mathrm{GmbH}$, Munich), $55 \mathrm{~g}$ per bar (fat 2,8 $\mathrm{g}+$ carbohydrates $35 \mathrm{~g}+$ protein $5,3 \mathrm{~g}$ ). Athletes were instructed to consume all the energy bars to avoid subestimation of food intake.

The athletes dressed accordingly during sailing sessions; light, non-restrictive attire was worn underneath life jackets, with neoprene wetsuit completely covering their bodies, arms, and legs. They were asked to maintain their usual dietary practices, but a special effort was made to athletes for recovering their body mass losses after sailing, with the aim of reaching their baseline body weight before the next session, especially when sessions were conducted on consecutive days.

\section{Measures}

Data collection was performed in A Coruña (Spain) during TS. RS measurements were obtained during the National Laser 4.7 Championship in Cádiz, Spain, May 2016; the European Laser 4.7 Championship in Crozon, France, July 2016; and the Laser Under-21 World Championships in Kiel, Germany, August 2016.

\section{Change in body mass}

Changes in body mass ( $\mathrm{g}$ ) over the sessions were defined as follows (equation 1):

$$
\text { (pre-exercise body mass (g) - post-exercise body mass(g) }
$$

\section{Sweat rate}

Changes in body mass, weight of food and water consumed, and duration of sessions were used to calculate SR (millilitres per hour), with the assumption $1 \mathrm{~kg}=1 \mathrm{~L}$, using the following formula ${ }^{24}$ (equation 2):

$$
\begin{gathered}
{[(\text { pre-exercise body mass }(g) \text { - post-exercise body mass }(g))} \\
+ \text { food }(g)+\text { fluid intake }] / \text { practice length }(h)
\end{gathered}
$$

\section{Percent of hypohydration (equation 3)}

Percentage change (PC) (\%) in fluid balance was calculated using the following formula ${ }^{24}$ (equation 3):

$$
\begin{gathered}
{[(\text { post-exercise body mass }(g) \text { - pre-exercise body mass }(g)) / p r e \text {-exercise }} \\
\text { body mass }(g)] \times 100
\end{gathered}
$$

This 'percentage of dehydration' assumes euhydration at the time of pre-launch weighing. 


\section{Windchill (equation 4)}

Windchill (WCh) is an index used to indicate how cold the weather feels to the average person. It is determined by combining temperature and wind velocity values into one number to reflect the perceived temperature.

$$
\text { TwC }=13.12+(0.6215 \times \mathrm{Ta})-\left(11.37 \times \mathrm{V}^{+0.16}\right)+\left(0.3965 \mathrm{~T} \times \mathrm{V}^{+0.16}\right)
$$

where Twc is the windchill index, based on the Celsius temperature scale, Ta is the air temperature in degrees Celsius, and $v$ is the wind speed at $10 \mathrm{~m}$ (33 ft) standard anemometer height in $\mathrm{km} \cdot \mathrm{h}^{-1}$.

\section{Duration of sessions}

The duration of sailing was also recorded, which is expressed as the time since the group of athletes' departure until the time of their arrival.

\section{Environmental conditions}

Environmental temperature, relative humidity, wind speed, and wind speed peaks were measured every 10 minutes using a portable weather station (Kestrel 3000 Pocket Weather Meter, Nielsen-Kelerman company, USA), in a boat as close as possible to the sailing area by the athletes'support crew. Main values were obtained for each session and then recorded for the study.

\section{Data analyses}

A descriptive analysis was be performed for all. Continuous variables were expressed as means \pm standard deviations or interquartile ranges. Dichotomous or categorical variables were expressed as absolute numbers and percentages. Pearson's or Spearman's correlation coefficient was used to determine the correlation between quantitative variables. All tests were two tailed, and a p value of $<.05$ was considered significant. Data were analysed using IBM SPSS Statistics 21

\section{Results}

About 202 valid measurements were obtained from 45 group sailing sessions (128 training and 74 racing); the number of measurements for each athlete depended upon their availability.

Data of those participants that evacuated their bladders while sailing were excluded from the analysis for that day (18 sessions). Up to eight sessions were not included in the study as the body mass of the athletes exceeded beyond the baseline measurement 15 minutes after arriving. Another five sessions were not included because of the variations in the environmental conditions during on-water period were more than $20 \%$.

Data were presented as the mean (range) for all descriptive statistics and within conditions, with the level of confidence set at $p<0.05$ to determine its significance unless specified.

\section{Duration of sessions (Table 2)}

Average of sailing session duration was 3,579 $\pm 1,532$ (h). The shortest session lasted for 30 minutes, and the longest session lasted for 495 minutes. The mean duration of TS was 3,0488 \pm 0,9495 (h) and that of racing sessions was 4,945 $\pm 1,664$ (h).
Table 2. Duration of sailing sessions, environmental factors and mean fluid/food intake.

\begin{tabular}{|c|c|c|c|c|}
\hline \multirow{3}{*}{$\begin{array}{l}\text { Characteristics of sessions } \\
\text { Number of sessions }\end{array}$} & \multicolumn{2}{|c|}{ Training sessions } & \multicolumn{2}{|c|}{ Racing sessions } \\
\hline & \multicolumn{2}{|c|}{128} & \multicolumn{2}{|c|}{74} \\
\hline & M & SD & M & SD \\
\hline Duration of sessions (h) & 3.05 & 0.95 & 4.95 & 1.66 \\
\hline \multicolumn{5}{|l|}{ Environmental factors } \\
\hline Environmental temperature $\left(\mathrm{C}^{\circ}\right)$ & 17.5 & 1.62 & 15.78 & 3.66 \\
\hline Relative humidity (\%) & 70.16 & 11.43 & 69.19 & 17.45 \\
\hline Wind speed $\left(\mathrm{km} \cdot \mathrm{h}^{1}\right)$ & 9.00 & 4.65 & 17.62 & 6.72 \\
\hline Wind speed peaks $\left(\mathrm{km} . \mathrm{h}^{\top}\right)$ & 16.58 & 6.11 & 24.12 & 9.04 \\
\hline \multicolumn{5}{|l|}{ Fluid and food intake } \\
\hline Mean fluid intake (ml) & 87.9 & 203 & 524 & 534 \\
\hline Mean food intake (g) & 34.9 & 105.6 & 64.6 & 64.1 \\
\hline Mean fluid intake per hour $\left(\mathrm{mL} \cdot \mathrm{h}^{-1}\right)$ & 9.3 & 67.8 & 104.8 & 106.2 \\
\hline Mean food intake per hour $\left(g \cdot h^{-1}\right)$ & 11.6 & 35.4 & 12.9 & 12.8 \\
\hline
\end{tabular}

All values except number of sessions are expressed as mean + /- standard deviation. "Fluid Intake" and "Food intake" are referred to mean intake along the sessions by person. "Mean inteake per hour" and "Mean fluid intake per hour" are referred to mean intake per hour by person.

\section{Mean fluid/meal intake (Table 2)}

The mean fluid intake during the TS was $88 \pm 203(\mathrm{ml})$ and that during RS was $524 \pm 534(\mathrm{ml})$. The mean food intake during the TS was $34,9 \pm 105,6(\mathrm{~g})$ and that during the RS $64,6 \pm 64,1(\mathrm{~g})$.

\section{Environmental conditions (Table 2)}

The mean environmental temperature, relative humidity, and wind velocity during TS were 17,50 \pm 1,62 $\left({ }^{\circ} \mathrm{C}\right), 67 \pm 17,55(\%)$, and 9,0 0 4,65 $\left(\mathrm{km} \cdot \mathrm{h}^{-1}\right)$, respectively, and those during RS were 15,78 $\pm 3.66\left({ }^{\circ} \mathrm{C}\right), 70,28$ $\pm 11,43(\%)$, and 17,62 $\pm 6,72\left(\mathrm{~km} \cdot \mathrm{h}^{-1}\right)$ respectively. The mean wind speed peak for TS was 16,58 $\pm 6,11\left(\mathrm{~km} \cdot \mathrm{h}^{1}\right)$ and that for RS 24,12 $\pm 9,04\left(\mathrm{~km} \cdot \mathrm{h}^{1}\right)$.

\section{Change in body mass}

The mean body mass changes during the TS were negative: -554 $\pm 432 \mathrm{~g}$ and that during RS was also negative: $-1121 \pm 387 \mathrm{~g}$.

\section{Sweat rate}

Significant differences in SR were found between TS and RS $(p=0.012)$. The mean SR during TS was $184,4 \pm 140,6 \mathrm{~mL} . \mathrm{h}^{1}$ and that during $\mathrm{RS}$ was $234,8 \pm 129,0 \mathrm{~mL} . \mathrm{h}^{1}$.

\section{Percentage of dehydration}

The mean percentage change in fluid balance during TS was -0.87 $\pm 0.69 \%$ (minimum: $0 \%$ and maximum: $-3.16 \%$, respectively). The mean percentage change in fluid balance during RS was $-1.73 \pm 0.99$ (minimum: 0\% and maximum: 3,93\%, respectively (Figure 1).

Changes in body mass and SR were described as the mean value \pm p25 and p75 values, respectively (Figure 1). 
Figure 1. Fluid balance and sweat rate expressed as mean \pm p25 and p75 standard deviation. Fluid balance and sweat rate were increased during racing sessions when compared to training sessions.

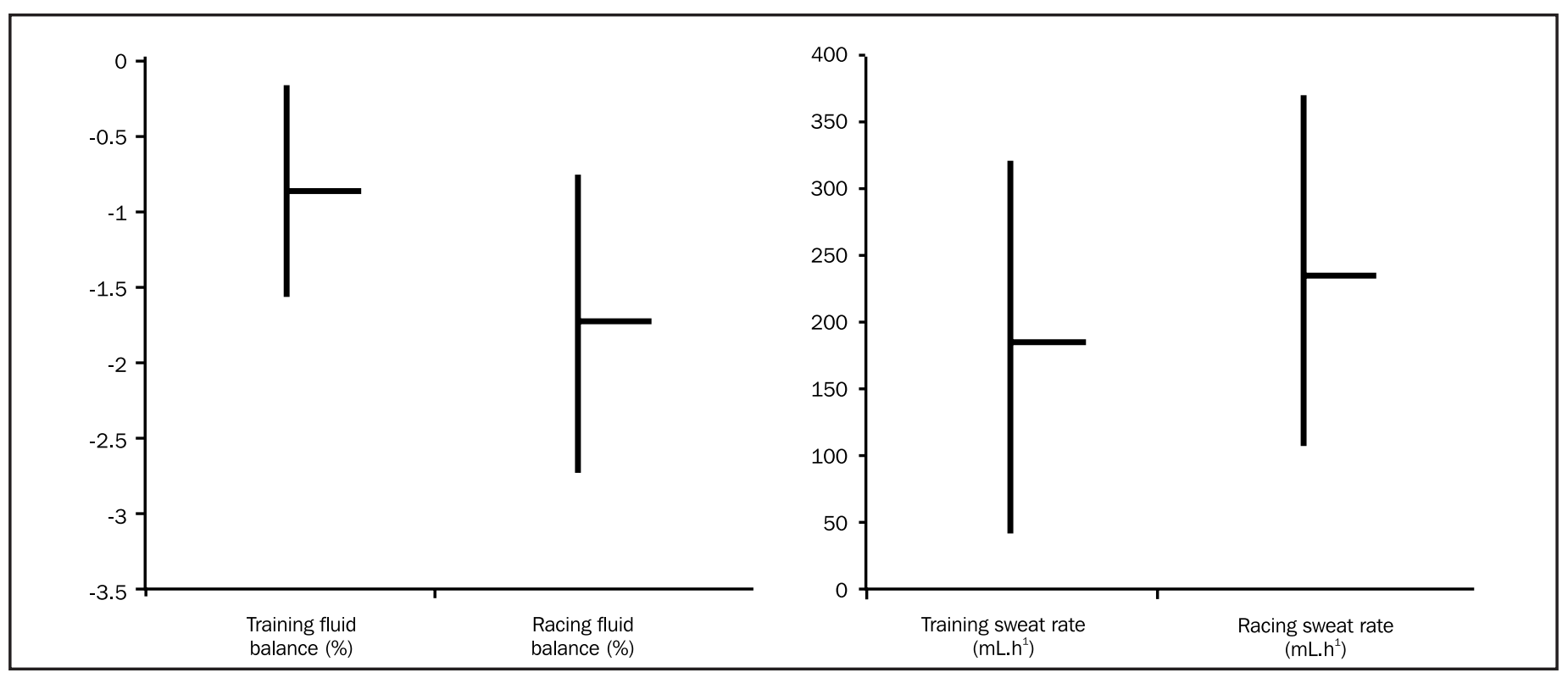

Figure 2. Sweat rate and "wind chill" for training and racing sessions. During racing sessions, an inverse correlation was found between "wind chill" and sweat rate; these data suggest that "wind chill" could be a good predictor on body mass losses during competition.
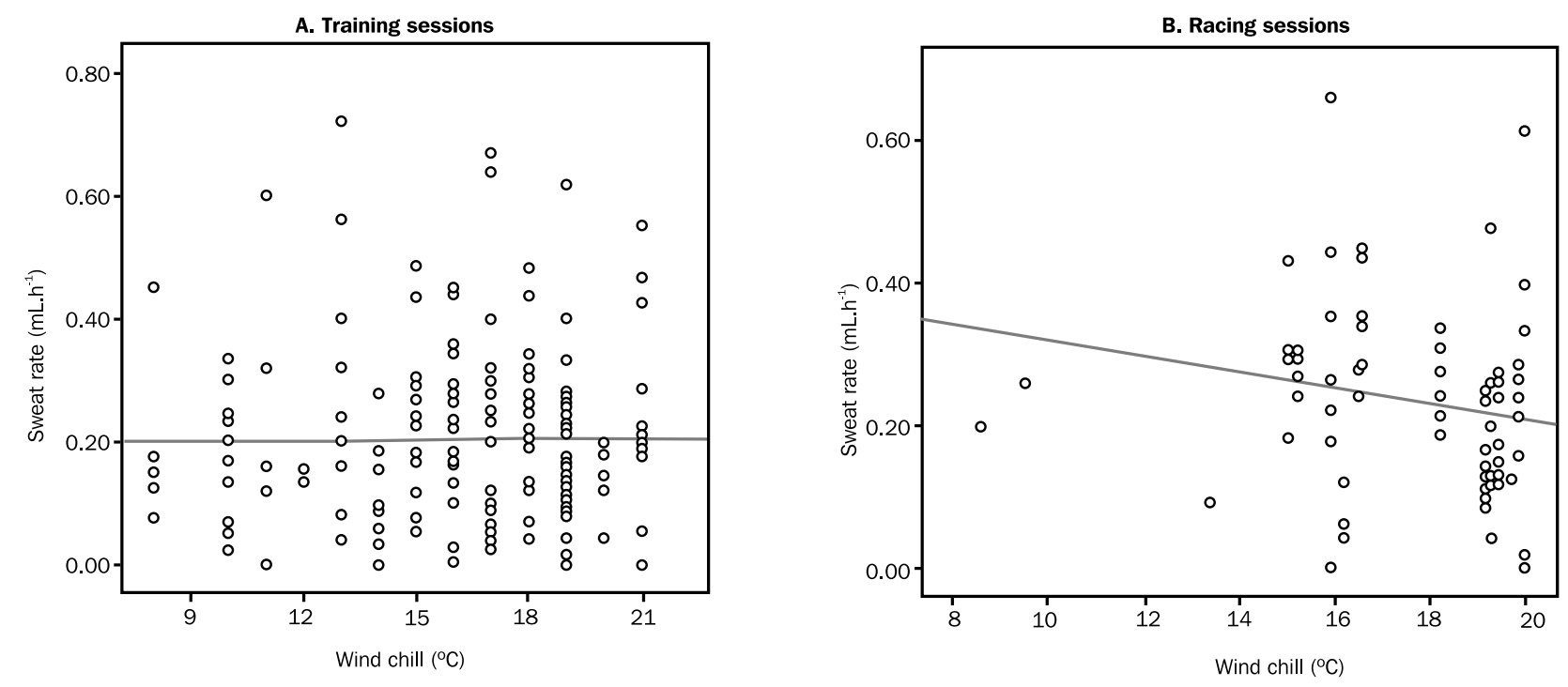

Sweat rate, percentage of dehydration, and environmental conditions

An inverse relationship was found between environmental temperature, WCh, and SR. This finding suggests that athletes would require not only an increased amount of fluid intake, but also a longer intake of carbohydrates when the environmental temperature is below $21^{\circ} \mathrm{C}$ and/or WCh is below $21^{\circ} \mathrm{C}$, to recover those metabolic losses (fluid and calories per hour) (Figure 2).

When analysed as independent variables, not environmental temperature, relative humidity, nor mean wind speed showed a significant statistic relationship with SR or percentage of dehydration after exercise. Our results have shown, however, a significant statistic relationship between peak wind speed and fluid requirements, but only during RS, not during TS. This could be explained by the intense performance during competitions (Figure 3). 
Figure 3. Significant statistic relationship between peak wind speed and fluid requirements was founded, but only during RS, not during TS. Not environmental temperature, relative humidity, nor mean wind speed showed a significant statistic relationship with SR or percentage of dehydration after exercise.

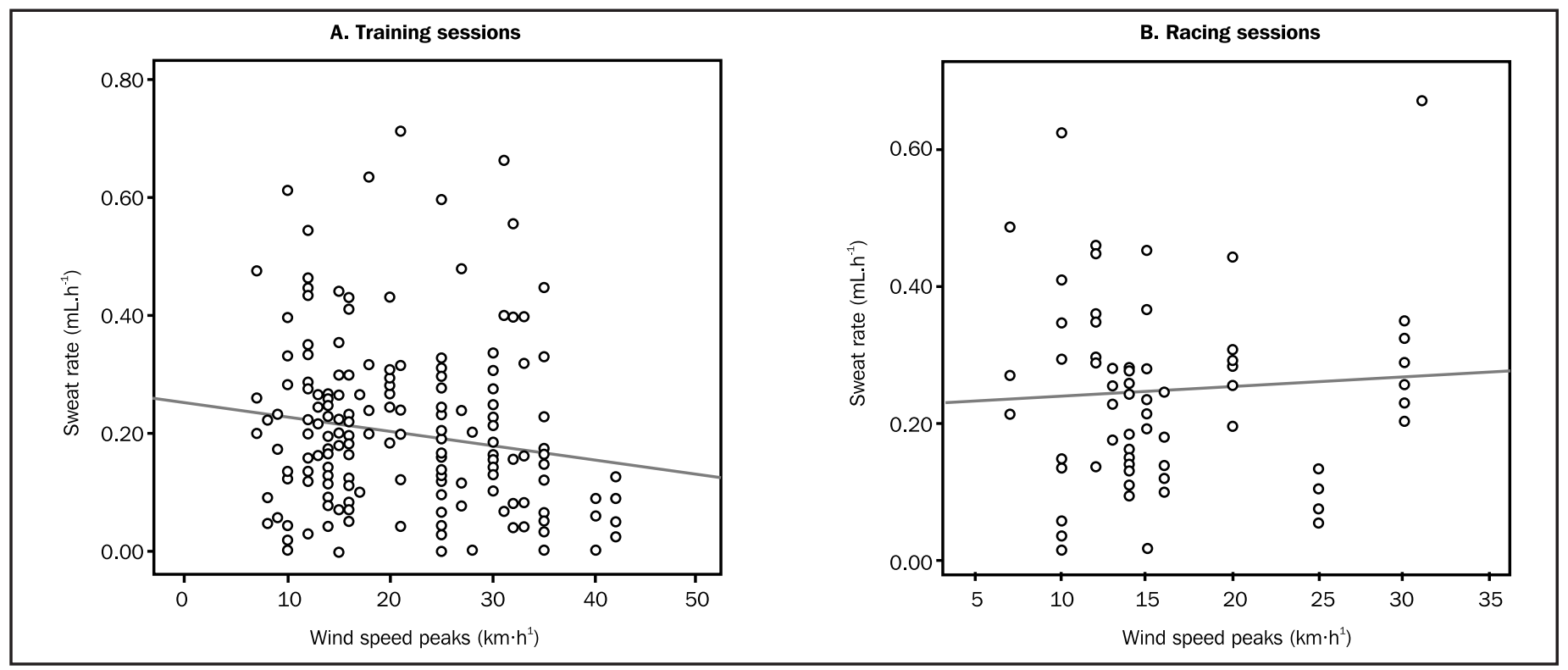

\section{Discussion}

Maintaining the 'target' weight for each sailor is a major factor for achieving better results during racing. This 'target' value depends on the body composition of each athlete and his tactical and strategical preferences during competitions. Variations in this 'target' weight for each sailor often imply poor athletic performance.

Our study showed that young elite sailors had insufficient fluid intake, even if they were instructed to consume enough fluids, which is consistent which other studies. Lewis et al. ${ }^{16}$ suggested that fluid requirements could be different for warm and cold conditions during TS: a recent study showed that a consumption of $11.5 \mathrm{~mL} . \mathrm{kg}^{-1} . \mathrm{h}^{-1}$ exceeded the requirements of different Olympic class sailors at warm conditions (environmental temperature: $19^{\circ} \mathrm{C}[17.0-23.3]$ ). The fluid requirements of the participants during WEC were anticipated to reflect the average laboratory SR of 1,470 mL.h ${ }^{-1}$ measured at $21.8^{\circ} \mathrm{C}$. The participant's average on-water SR was only $611.8 \pm 47.2 \mathrm{~mL} . \mathrm{h}^{-1}$. This rate was $41.5 \%$ lower than the pre-study laboratory SR of 1,470 mL.h-1. However, at CEC, participants had ab libitum fluid consumption, which indicated that 'they arrived for training in a borderline hypohydrated state' after attending a 2.5-hour RS 25 .

In contrast, we found a significant difference $(p=0.012)$ in $S R$ between TS and RS, suggesting that increased liquid intake is needed during racing, regardless of the weather condition.

In our study, the inverse relationship between SR and some isolated environmental factors like temperature $\left(<21^{\circ} \mathrm{C}\right)$ as well as the direct relationship between $\mathrm{SR}$ and wind speed peaks under racing conditions were considered as important factors for predicting the fluid and food requirements in young sailors before racing or training depending on the weather condition.
This study had some limitations. The study only included 'high-skilled'young sailors. The results were inconsistent as the level of technical and physical performance differed between athletes.

Although our results were in agreement with those of previous studies with similar populations, further investigations are necessary to confirm the influence of EC and determine a better strategy to help reduce the impact of these factors on the study results. The possibility of using WCh as a global environmental indicator should be analysed and discussed to confirm its accuracy as a predictive factor.

\section{Acknowledgements}

This work was supported, in part, by Clinical Researching Committee-Unidad de Investigación Clínica y Ensayos Clínicos (UICEC) of

A Coruña (Spain). Additionally, we would like to thank the Biomedical Research Institute of A Coruña (INIBIC) for assistance with data analysis.

Any opinions, conclusions, or recommendations expressed here are those of the authors.

\section{Conflict of interest}

The authors declare no conflict of interest.

\section{Bibliography}

1. Sawka MN, Burke LM, Eichner ER, Maughan RJ, Montain SJ, Stachenfeld NS. Medicine position stand. Exercise and fluid replacement American College of Sports. Med Sci Sports Exerc. 2007;39:377-90.

2. Hargreaves M, Dillo P, Angus D, Febbraio M. Effect of fluid ingestion on muscle metabolism during prolonged exercise. J Appl Physiol. 1996;80:363-6.

3. Coyle E. Fluid and fuel intake during exercise. J Sports Sci. 2004;22:39-55. 
4. D'anci KE, Vibhakar A, Kanter JH, Mahoney CR, Taylor HA. Voluntary dehydration and cognitive performance in trained college athletes. Percept Mot Skills. 2009;109:251-69.

5. Casa DJ, Stearns RL, Lopez RM, Ganio MS, Mcdermott BP, Yeargin SW, et al. Influence of hydration on physiological function and performance during trail running in the heat. J Ath/ Train. 2010;45:147-56.

6. Passe D, Horn M, Stofan J, Horswill C, Murray R. Voluntary dehydration in runners despite favourable conditions for fluid intake. Int J Sport Nutr Exerc Metab. 2007;17:284-95.

7. Arnaoutis G, Kavouras SA, Angelopoulou A, Skoulariki C, Bismpikou S, Mourtakos S, et al. Fluid balance during training in elite young athletes of different sports. J Strength Cond Res. 2015;29(12):3447-52.

8. Hew-Butler TD, Eskin C, Bickham J, Rusnak M, VanderMeulen M. Dehydration is how you define it: comparison of 318 blood and urine athlete spot checks. BMJ Open Sport Exerc Med. 2018;4: e000297

9. Armstrong, Johnson \& Bergeron. Couterview: Is drinking to thirst adequate to appropriately maintain hydration status during prolonged endurance exercise? Wild Env Med. 2016;Jun;27(2):195-8

10. Barr SI. Effects of dehydration on exercise performance. Can J Appl Physiol. 1999; 24(2):164-72.

11. Sawka MN. Physiological consequences of hypohydration: exercise performance and thermoregulation. Med Sci Sports Exerc. 1992;24:657-70.

12. Carlton A, Orr RM. The effects of fluid loss on physical performance: a critical review. J Sport Health Sci. 2015;4:357-63.

13. Coyle E, Montain S. Benefits of fluid replacement with carbohydrate during exercise. Med Sci Sports Exerc. 1992;24:S324-30.

14. Allen JB, De Jong MR. Sailing and sports medicine: a literature review. Br J Sports Med. 2006;40:587-93.
15. Vogiatzis I, Spurway NC, Jennett S, Wilson J, Sinclair J. Changes in ventilation related to changes in electromyograph activity during repetitive bouts of isometric exercise in simulated sailing. EurJ Appl Physiol Occup Physiol. 1996;2:195-203.

16. Lewis EJ, Fraser SJ, Thomas SG, Wells GD. Changes in hydration status of elite Olympic class sailors in different climates and the effects of different fluid replacement beverages. J Int Soc Sports Nutr. 2013;21;10(1):11.

17. Slater $G$, Tan B. Body mass changes and nutrient intake of dinghy sailors while racing. J Sports Sci. 2007;25:1129-35.

18. Castagna O, Brisswalter J. Assessment of energy demand in laser sailing: influences of exercise duration and performance level. Eur J Appl Physiol. 2007;99:95-101.

19. Mackie H, Sanders R, Legg S. The physical demands of Olympic yacht racing. J Sci Med Sport. 1999;2:375-88.

20. De Vito G, Di Filippo L, Felici F, Gallozzi C, Madffari A, Marino S, et al. Assessment of energetic cost in laser and mistral sailors. Int J Sport Cardiol. 1996;5:55-9.

21. Legg SJ, Smith PA, Slyfield D, Miller AB, Wilcox H, Gilberd C. Knowledge and reported use of sport science by elite New Zealand Olympic class sailors. J Sports Med Phys Fitness. 1997;37:213-17.

22. Legg SJ, Mackie HW. Change in knowledge and reported use of sport science by elite New Zealand Olympic class sailors. J Physiol Anthropol App/ Human Sci. 2000;19:83-92.

23. Arnaoutis G, Verginadis P, Seal AD, Vogiatzis I, Sidossis LS, Kavouras SA. Progressive dehydration in junior laser class sailors during world championship. Int J Sport Nutr Exerc Metab. 2018;28(1):75-81.

24. Vogiatzis I, Spurway NC, Wilson J, Boreham C. Assessment of aerobic and anaerobic demands of dinghy sailing at different wind velocities. J Sports Med Phys Fitness. 1995b;35:103-7.

25. Cunningham P, Hale T. Physiological responses of elite Laser sailors to 30 minutes of simulated upwind sailing. J Sports Sci. 2007;25:1109-16. 